Article

\title{
Design Optimization of the Aeronautical Sheet Hydroforming Process Using the Taguchi Method
}

\author{
Aurelio Muñoz-Rubio ${ }^{1}$, David Bienvenido-Huertas ${ }^{2, *}$ (D), \\ Francisco Javier Bermúdez-Rodríguez ${ }^{3}$ (D) and Manuel Tornell-Barbosa 4 \\ 1 Department of Naval Constructions, University of Cadiz, 11519 Puerto Real, Spain; aurelio.munioz@uca.es \\ 2 Department of Graphical Expression and Building Engineering, University of Seville, 41012 Seville, Spain \\ Department of Thermal Machines and Motors, University of Cadiz, 11519 Puerto Real, Spain; \\ javier.bermudez@uca.es \\ 4 Department of Mechanical Engineering and Industrial Design, University of Cadiz, 11519 Puerto Real, Spain; \\ manuel.tornell@uca.es \\ * Correspondence: jbienvenido@us.es; Tel.: +34-954-556-626
}

Received: 8 April 2019; Accepted: 30 April 2019; Published: 10 May 2019

check for updates

\begin{abstract}
The aluminium alloy sheet forming processes forging in rubber pad and diaphragm presses (also known as hydroforming processes) are simple and economical processes adapted to aeronautical production. Typical defects of these processes are elastic recovery, necking, and wrinkling, and they present difficulties in control mainly due to property variations of the sheet material that take place during the process. In order to make these processes robust and unresponsive to material variations, a multiobjective optimization methodology based on the Taguchi method is proposed in the present study. The design of experiments and process simulation are combined in the methodology, using the nonlinear finite element method. The properties of sheet material are considered noise factors of the hydroforming process, the objective being to find a combination of the control factors that causes minimal defects to noise factors. The methodology was applied to an AA2024-T3 aluminium alloy sheet of $1 \mathrm{~mm}$ thickness stamping process in a diaphragm press. The results allowed us to establish the optimal pressure values, friction coefficient between sheet and block, and friction coefficient between sheet and rubber to reduce the elastic recovery variations and the minimal thickness before noise facts.
\end{abstract}

Keywords: Taguchi method; hydroforming process; aeronautical sheet

\section{Introduction}

In recent years, the development of new aluminium alloys adapted to the specific needs of every part of the aircraft, lighter, more resistant to corrosion, more tolerant to damage, weldable, and cheaper than carbon fibre, has allowed the aluminium alloy sheet to continue having an important presence in aeronautical structures, as demonstrated in the new generations of single-aisle aircraft.

Aluminium alloy sheet forming processes forging in rubber pad presses, also known as hydroforming processes, were developed in the 20th century with the arrival of metallic fuselage aircraft to be able to use a more economical and faster method than manual forming [1].

By means of hydroforming, the contour flaps are folded into sheet pieces from 0.5 to $3 \mathrm{~mm}$, with a flat core, generally belonging to ribs or to aeronautical structural elements. The flaps are used to join other pieces by rivets and can be straight or curved (concave, convex, or mixed). Also, by means of hydroforming, smaller stampings are formed in the core of the pieces whose objective is to increase the rigidity without increasing the weight of the piece. In these stampings, the pressure acts on a free radius, forming the sheet by biaxial membrane tensions in the area of the sheet that is in contact with 
radiuses of the block, and bending stresses are generated accompanied by the traction produced by the dragging of the rubber.

The variability in the results is an unsolved problem in hydroforming, considering that it can lead to the need for unproductive operations on the finished piece to return it to the desired shape, as in the case of distortions caused by elastic recovery, or to render it unusable by localised necking or ductile fracture [2]. For a given geometry, the appearance of defects depends on parameters directly related to the hydroforming process, such as: (i) technological parameters (like the pressure, the hardness of the rubber, the friction between the sheet and the rubber or between the sheet and the forming block), and (ii) parameters related to the formability of the sheet (like Young's module, the strength coefficient, the anisotropy indexes or the hardening exponent of the material). The technological parameters of the process are controllable, while the parameters related to the formability of the sheet are difficult to control or it is expensive to reduce their variability. The main defects that appear in the hydroforming are the breaks produced by high tensile stresses, the elastic recovery that takes place when diminishing the forces of the forming, changing the form of the piece, and the wrinkles that occur when shaping the sheet in areas with less perimeter (see Figure 1).

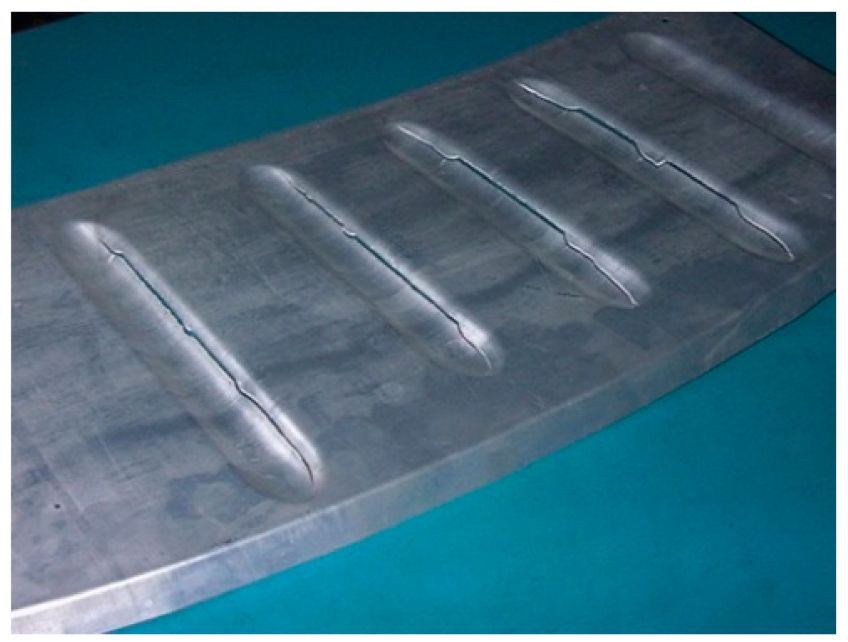

Figure 1. Cracks due to necking in the radius of the stamping tool.

Different studies have analyzed aspects for the optimization of hydroforming processes. For example, (i) Mahabunphachai and Koc [3] studied the microhydroforming process of metallic sheets considering the flow stress size effect. The authors used the hydraulic pumping test to investigate the size effects of the material, both grain size and specimen size. The results determined that the material flow curves decrease when reducing both relations; (ii) a similar study was carried out by Xu et al. [4]. In their work, the authors analyzed the relationship between the geometry and the grain size on copper sheet hydroforming processes. The results showed that as the grain size approaches the thickness of the sheet, the maximum formation height and the final pressure decrease; (iii) Capece Minutolo et al. [5] used finite element methods to reduce the production process of aeronautical materials from four to three steps. The results allowed them to reduce the time of production, although the thinning process constitutes the longest process, due to the combination of other subprocesses; and (iv) Reveles Arrebondo et al. [6] developed a methodology for determining the hydraulic pressure necessary to perform hydroforming processes in noncircular pieces. The results achieved reductions of $5.5 \%$ in the thickness of the pieces.

Nevertheless, there is a gap in the knowledge of studies that analyze the optimization of aeronautical sheet hydroforming processes. In this scenario, the need arises to make the aeronautical sheet hydroforming processes more competitive. Generally, the forging aeronautical aluminium alloy sheet is received in an annealed condition and is formed in a fresh and unstable state following the heat treatment solution. In order to avoid the loss of ductility and the increase in the resistance that occurs in 
natural maturation, it is necessary to keep the sheet in the refrigerator at $-40^{\circ} \mathrm{C}$; this operation generates an important variability of the parameters related to the formability of the sheet. This variability occurs both within the same batch of pieces and between different batches. Being able to shape the sheet after its maturation, in a steady state T3, with lower ductility and greater resistance, could be an important competitive advantage for hydroforming; it would reduce the variability originating in the parameters related to the formability, but it would increase the risk of cracking by necking or by ductile fracture.

Therefore, in this study, the robust design methodology of Taguchi has been employed $[7,8]$. This was due to the good results in other industrial hydroforming processes, such as the one carried out by Reddy, Reddy, and Rao [9]. In this work, the authors optimized the pipe hydroforming process for the construction of complex automotive parts. Also, in another work by Tilak and Nagaraju [10], they analyzed the use of the methodology to optimize the cutting process on 1100 aluminium alloy surfaces. Therefore, the possibilities of application of this methodology constitutes an opportunity for the optimization of aeronautical sheet hydroforming processes, so the robust design methodology was applied to make the process less sensitive to the inherent variations [11]. The aim was to make that the elastic recovery and the thinning of the sheet in the stamping area minimal and insensitive to variations in the material. Technological parameters were considered as control factors of the process, while the noise factors were the parameters related to the formability of the sheet, and process simulation tools were used by means of the Finite Elements Method (FEM), from the conceptual design phase of the pieces until the design of the forming blocks.

The article is structured as follows: (i) in Section 2, a detailed description of Taguchi's robust design methodology and its applications in engineering is made; (ii) Section 3 describes the methodology used in this study; (iii) Section 4 discusses the results obtained; and (iv) Section 5 establishes the main conclusions of the study.

\section{Taguchi's Robust Design Method}

The classical analysis of conducting trials to optimize production processes by analyzing several factors is usually a complex process with high time consumption [12]. In the case of statistically designed experiments, several individual experiments are performed simultaneously. However, there are problems such as the sequence of the experiments to be performed and the analysis of the influence of different independent variables analyzed during the trials. Given these aspects, Genichi Taguchi established a methodology for the design of factorial experiments that would allow optimizing productive processes $[7,8]$. This methodology emphasizes the use of fractional factorial designs and other orthogonal matrices in novel ways with the purpose of achieving four aspects [13]: (i) manufacture products that are robust to environmental conditions; (ii) make the products insensitive to the variation of components; (iii) minimizing the mean square error over an objective value; and (iv) greater reliability and product life.

The experiments planned statistically with the Taguchi methodology allow one to recognize and characterize those parameters of the analyzed process that reduce the variation of their performance [14]. Additionally, the Taguchi methodology has been widely applied in developmental trials, consisting of the detection of the optimal configurations of the analyzed parameters of a process through a reduced number of experiments [7]. Therefore, the application of the Taguchi methodology allows one to optimize the process quickly [15].

The experiments are designed in the form of orthogonal matrices. These experiments include several individual experiments that should be performed in a random manner. In this way the error is reduced, and the efficiency of the results is improved. For identification, the level indicator " $\mathrm{L}$ " and the number of trials performed are used. Thus, experiments of type L4, L9, and L18 can be configured with 4,9 , and 18 trials, respectively.

To understand the methodology, it is fundamental to distinguish two types of factors. All the processes analyzed by the Taguchi methodology are affected by a series of controllable and noncontrollable factors. Noncontrollable factors (also known as noise factors) make it difficult to 
achieve desirable quality levels. In practice, they are usually factors whose control requires high economic investment. The main aim of the robust design of a process is to reduce the sensitivity of noise factors [16]. The signal-to-noise index (SN) establishes the quality and shows the relationship between control factors and noise factors, allowing one to determine the most robust design [17].

The use of orthogonal arrays allows analyzing different combinations of control factors and noise factors. To determine the effect of each factor, SN should be calculated in each experiment. For this, the following equations are used:

$$
\begin{gathered}
S N_{i}=10 \log \frac{y^{2}}{s^{2}} \\
y_{i}=\frac{1}{N_{i}} \sum_{u=1}^{N_{i}} y_{i, u} \\
s_{i}=\frac{1}{N_{i}-1} \sum_{u=1}^{N_{i}}\left(y_{i, u}-\bar{y}_{i}\right)
\end{gathered}
$$

where $i$ is the experiment number, $y_{i}$ is the value of the behavioural characteristic for a given experiment, $\bar{y}_{i}$ is the average value, $s_{i}$ is the variance, $N_{i}$ is number of trials for experiment $i$, and $u$ is the trial number.

Depending on the process analyzed, it should be sought to minimize or maximize the performance characteristic. For this purpose, the definition of the SR relationship should meet the condition of Equation (4) to minimise the performance characteristic, or the condition of the Equation (5) to maximize the performance characteristic:

$$
\begin{gathered}
S N_{i}=-10 \log \left(\sum_{u=1}^{N_{i}} \frac{y_{u}^{2}}{N_{i}}\right) \\
S N_{i}=-10 \log \left(\frac{1}{N_{i}} \sum_{u=1}^{N_{i}} \frac{1}{y_{u}^{2}}\right)
\end{gathered}
$$

By doing so, this methodology is widely applied in different fields of engineering (see Table 1), since it allows the development of quality products and to reduce the research periods and the delivery time of the products [18]. Furthermore, the performance of the analysis obtained with the Taguchi method allows obtaining similar results to other advanced statistical techniques. In this sense, Aggarwal et al. [19] conducted a comparative study between the Taguchi technique and the response surface methodology to optimize the energy consumption for turned parts controlled numerically by a computer. The methods obtained similar results, although the time required for the Taguchi methodology was less. For all these reasons, the use of this methodology constitutes an opportunity to optimize the hydroforming process of aeronautical sheets. 
Table 1. Examples of applications using the Taguchi methodology in different products or processes in the field of engineering.

\begin{tabular}{|c|c|c|}
\hline Product or Process & Experimental Design & Reference \\
\hline $\begin{array}{l}\text { Optimization of the injection-molding process } \\
\text { for friction properties of fiber-reinforced } \\
\text { polybutylene terephthalate (PBT). }\end{array}$ & L9 & Fung and Kang [20] \\
\hline $\begin{array}{l}\text { Optimization of the injection process of } \\
\text { polypropylene moldings. }\end{array}$ & $\mathrm{L}_{8}$ & Reddy, Nishina and Subash Babu [21] \\
\hline $\begin{array}{l}\text { Reduce the variability in the Ride comfort of a } \\
\text { vehicle with respect to sprung mass of vehicle. }\end{array}$ & $\mathrm{L}_{8}$ & Mitra et al. [22] \\
\hline $\begin{array}{l}\text { Optimization of the synthesis conditions of } \\
\text { N-doped } \mathrm{TiO}_{2} \text { nanoparticles. }\end{array}$ & $\mathrm{L}_{9}$ & $\begin{array}{c}\text { Katoueizadeh, Zebarjad and } \\
\text { Janghorban [23] }\end{array}$ \\
\hline $\begin{array}{l}\text { Optimization of autonomous } \\
\text { photovoltaic system. }\end{array}$ & $\mathrm{L}_{9}$ & Hong, Beltran and Paglinawan [24] \\
\hline $\begin{array}{l}\text { Maximize the impact resistance of hybrid } \\
\text { welded steel and aluminum structures. }\end{array}$ & $\mathrm{L}_{9}$ & Sun et al. [25] \\
\hline $\begin{array}{l}\text { Optimization of the } \mathrm{SnO}_{2} \text { thin film deposition } \\
\text { process design. }\end{array}$ & $\mathrm{L}_{9}$ & Ebrahimiasl et al. [26] \\
\hline $\begin{array}{l}\text { Optimization of tensile strength of duplex } \\
\text { stainless steel } 2205 .\end{array}$ & $\mathrm{L}_{9}$ & Naik and Reddy [27] \\
\hline $\begin{array}{l}\text { Optimization of laser powder deposition } \\
\text { parameters to get an alloy of AlSi10Mg with } \\
\text { maximum density. }\end{array}$ & $\mathrm{L}_{25}$ & Liu et al. [28] \\
\hline $\begin{array}{l}\text { Optimization of the machining process for the } \\
\text { roughness of the surface of materials. }\end{array}$ & $\mathrm{L}_{9}$ & Kumar, Agarwal and Srivastava [29] \\
\hline $\begin{array}{l}\text { Optimization of the penetration rate in rotary } \\
\text { percussive drilling of machines. }\end{array}$ & $\mathrm{L}_{18}$ & $\begin{array}{l}\text { Derdour, Kezzar and } \\
\text { Khochemane [30] }\end{array}$ \\
\hline
\end{tabular}

\section{Methodology}

\subsection{Case Study}

The case study selected was an AA2024-T3 aluminium alloy sheet of $1 \mathrm{~mm}$ thickness stamping process in diaphragm press (see Figure 2). The aim was to ensure that the elastic recovery and thinning of the sheet in the stamping area were minimal and insensitive to material variations by optimizing the production process.

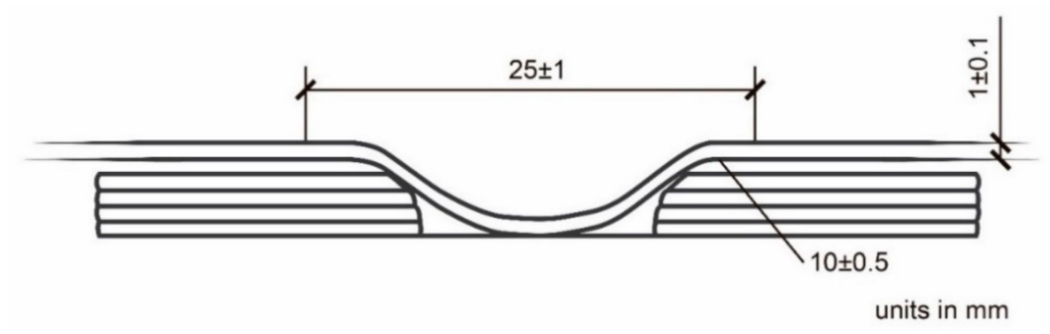

Figure 2. Straight section of the proposed stamping.

\subsection{Methodological Process}

Figure 3 shows the flowchart followed in the investigation. In the first step, an analysis of the weaknesses of the hydroforming process in aeronautical sheets was carried out. To this end, meetings were held with specialized personnel to identify control and noise factors, and test conditions. Subsequently, the experiments were carried out and the obtained results were analyzed. 


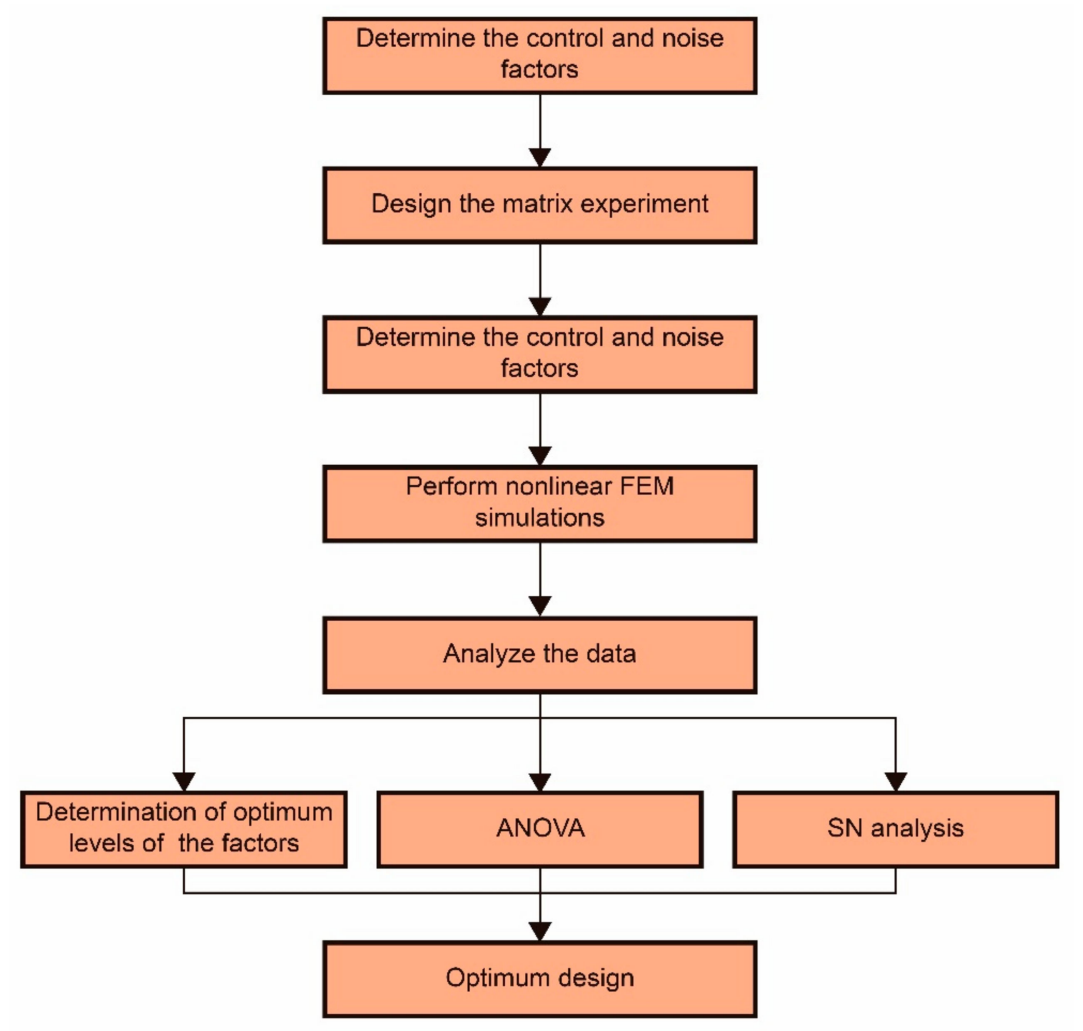

Figure 3. Flowchart followed in the investigation.

An $\mathrm{L}_{4}$ experimental design (i.e., of four trials) was carried out with six study factors (see Table 2): (i) three control factors (pressure $(P)$, friction coefficient between the sheet and the rubber $\left(\rho_{\text {sh-rubb }}\right)$ and friction coefficient between the sheet and the block $\left.\left(\rho_{s h-b l o}\right)\right)$ in an internal orthogonal matrix or arrangement, and (ii) three noise factors (hardening exponent $(n)$, strength coefficient $(K)$ and Young's modulus $(E)$ ) in an external orthogonal matrix or arrangement. These values have been obtained by the law of elastoplastic behaviour of material (Swift or Krupkowski type) and from the results of tensile tests. Also, those of the noise factors are obtained based on standardized trials with the sheet material.

Table 2. Cross array design.

\begin{tabular}{|c|c|c|c|c|c|c|c|c|}
\hline \multicolumn{4}{|c|}{ Inner Array } & \multicolumn{5}{|c|}{ Outer Array } \\
\hline \multirow[b]{2}{*}{ No. } & \multicolumn{3}{|c|}{ Control Factors } & \multicolumn{5}{|c|}{ Noise Factors } \\
\hline & $P(\mathrm{MPa})$ & $\rho_{\text {sh-rubb }}$ & $\rho_{\text {sh-blo }}$ & $\begin{array}{c}n \\
K(\mathrm{MPa}) \\
E(\mathrm{GPa})\end{array}$ & $\begin{array}{c}0.088 \\
636 \\
61\end{array}$ & $\begin{array}{c}0.146 \\
726 \\
61\end{array}$ & $\begin{array}{c}0.146 \\
636 \\
71\end{array}$ & $\begin{array}{c}0.088 \\
726 \\
71\end{array}$ \\
\hline 1 & 50 & 0.2 & 0.1 & & $\eta_{11}$ & $\eta_{11}$ & $\eta_{13}$ & $\eta_{14}$ \\
\hline 2 & 50 & 0.5 & 0.2 & & $\eta_{21}$ & $\eta_{22}$ & $\eta_{23}$ & $\eta_{24}$ \\
\hline 3 & 60 & 0.2 & 0.2 & & $\eta_{31}$ & $\eta_{32}$ & $\eta_{33}$ & $\eta_{34}$ \\
\hline 4 & 60 & 0.5 & 0.1 & & $\eta_{41}$ & $\eta_{42}$ & $\eta_{43}$ & $\eta_{44}$ \\
\hline
\end{tabular}

With the combination of control and noise factors, it was necessary to carry out 16 trials. The trials were simulated by nonlinear FEM. For this, the PAM-STAMP software was used. For the sheet material, an anisotropic yield function Hill'48 incorporated in PAM-STAMP and an isotropic hardening during plastic deformation were considered. Therefore, the values required of the AA2024-T3 sheet of $1 \mathrm{~mm}$ for tensile tests at $0^{\circ}, 45^{\circ}$, and $90^{\circ}$ according to the ASTM E8/E8M-08 and ASTM E132-04 standards and for anisotropy indexes according to ASTM E517-00 at $0^{\circ}, 45^{\circ}$, and $90^{\circ}$. For the conformation limit 
curves, tests of Nakajima are carried out according to the ISO 12004-2 standard to simulate the various deformation states in the sheet.

For the elastomer of the diaphragm (a polyurethane of $70^{\circ}$ Shore A of hardness and of $6 \mathrm{~mm}$ of thickness) a nonlinear hyperelastic model of Mooney-Rivlin was considered, formulating the strain energy by using the Mooney-Rivlin model according to the strain invariants incorporated in PAM-STAMP. By doing so, the values of the elastic recovery in the stamping area were obtained (as the maximum distance $d(\mathrm{~mm})$ ) to the block in the stamping area, and the thinning (as the minimum thickness $t_{\min }(\mathrm{mm})$ ), to assess the necking risk. The sheet, the diaphragm rubber and the conformation block are milled with square elements of type Shell (Belytschko-Tsay) of reduced integration. The results indicated that $5 \mathrm{~mm}$ for the mesh is acceptable, being the same size of mesh for the diaphragm rubber and the conformation block. To describe both the sheet-rubber and the sheet-block contacts, the method based on the Lagrange multipliers is used.

The proposed modification of the Taguchi methodology to perform multiobjective optimization consists of defining an optimization function by means of two loss functions (see Figure 4). These loss functions are associated with elastic recovery (see Equation (6)) and thinning (see Equation (7)). The optimization function $\left(f_{\text {opt }}\right)$, coincides with the sum of the areas of the two shaded triangles of Figure 4, multiplied by weight factors (see Equation (8)). The two weight factors will fulfil the condition $\beta+\gamma=1$. The mean SN ratios were calculated. An analysis of variance (ANOVA) was performed to statistically analyze the importance of each factor for its optimization.

$$
\begin{gathered}
\mu_{d}=1-\frac{d}{d_{\max }} \\
\mu_{t}=1-\frac{t_{\min }}{t_{0}} \\
f_{\text {opt }}=\gamma \frac{d\left(1-\mu_{d}\right)}{2}+\beta \frac{\mu_{t}\left(1-t_{\min }\right)}{2}
\end{gathered}
$$

where $d$ is the elastic recovery value obtained in the simulation, $d_{\max }$ is the maximum value of elastic recovery obtained in the simulation, $t_{0}$ is the initial thickness $(1 \mathrm{~mm}), t_{\min }$ is the minimum thickness obtained in the simulation, and $\gamma$ and $\beta$ are the weight factors of the optimization function.

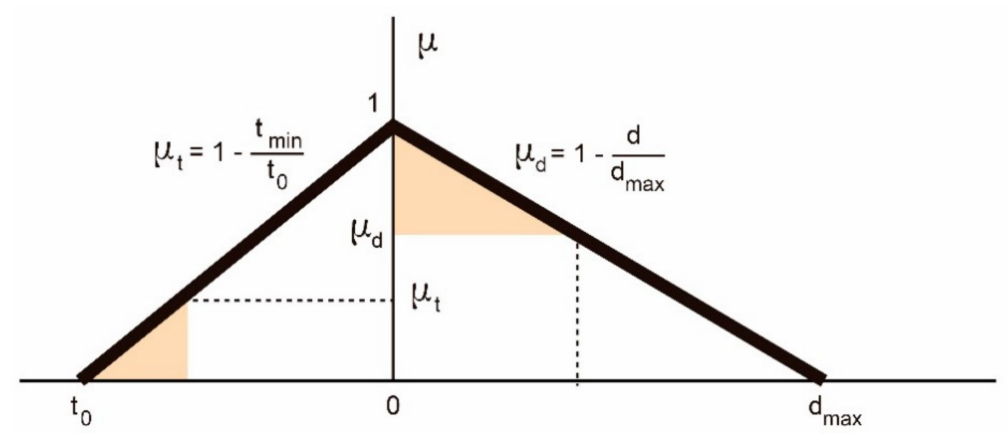

Figure 4. Loss functions associated with thinning and elastic recovery.

\section{Results and Discussion}

As already indicated, a total of 16 trials were performed using FEM simulations. By means of these simulations, it was possible to analyze the elastic recovery in the stamping area (see Figure 5) and the minimum thickness (see Figure 6). Tables 3 and 4 reflect the results of elastic recovery and minimum thickness, respectively. It can be seen how the values of $d$ oscillated between 0.75 and 7.25 , while the oscillations of $t_{\min }$ had less variations, with values that ranged between 0.84 and 0.90 . Therefore, it was important to optimise the forming process factors to conclude that the thinning and elastic recovery of the sheet was minimal. 
Distance between objects (physical)

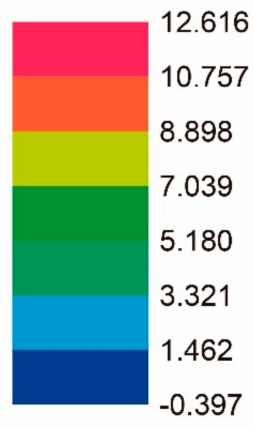

Min $=-0.397$

$\operatorname{Max}=12.616$

Figure 5. Simulation of the maximum distance to the block in the stamping area.

\section{Thickness}
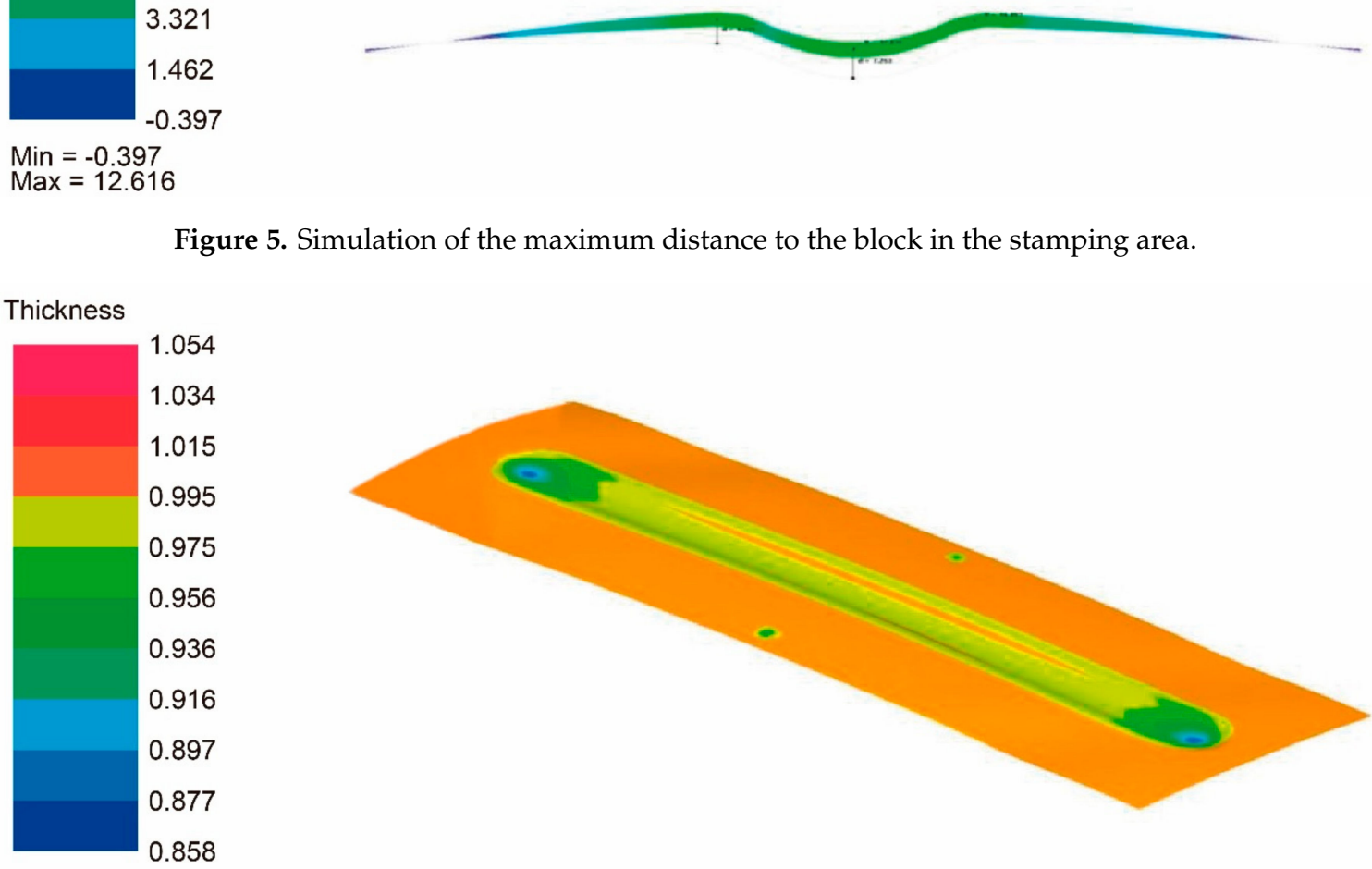

$\operatorname{Min}=0.858$

Max $=1.054$

Figure 6. Simulation of the minimum thickness $t_{\min }(\mathrm{mm})$ in the stamping area.

The optimization problem is reduced by minimizing the optimization function. For this, the $\mathrm{SN}$ ratio of Equation (4) should be used. The results of applying this function and the mean of the optimization function, obtained with the values of the elastic recovery, and the thinning of the simulation obtained with FEM (Tables 3 and 4, respectively) are represented in Table 5, while the main effect diagrams are represented in Figure 7. The values of the optimization functions were obtained with the weight functions $\beta=0.9$ and $\gamma=0.1$. In order to reduce the variability of the optimization function, it was necessary to maximize the SN statistical index, and to minimize the optimization function it was necessary to minimize the mean.

Table 3. Results of the elastic recovery $\mathrm{d}(\mathrm{mm})$ obtained from the simulation by the FEM (the results are represented in the values in bold).

\begin{tabular}{|c|c|c|c|c|c|c|c|c|}
\hline \multicolumn{4}{|c|}{ Inner Array } & \multicolumn{5}{|c|}{ Outer Array } \\
\hline \multirow{4}{*}{ No. } & \multicolumn{3}{|c|}{ Control Factors } & \multicolumn{5}{|c|}{ Noise Factors } \\
\hline & & & & $n$ & 0.088 & 0.146 & 0.146 & 0.088 \\
\hline & $P(\mathrm{MPa})$ & $\rho_{\text {sh-rubb }}$ & $\rho_{\text {sh-blo }}$ & $K(\mathbf{M P a})$ & 636 & 726 & 636 & 726 \\
\hline & & & & $E(\mathrm{GPa})$ & 61 & 61 & 71 & 71 \\
\hline 1 & 50 & 0.2 & 0.1 & & 2.14 & 0.78 & 0.75 & 1.18 \\
\hline 2 & 50 & 0.5 & 0.2 & & 7.25 & 3.39 & 1.56 & 7.11 \\
\hline 3 & 60 & 0.2 & 0.2 & & 2.21 & 4.43 & 1.90 & 1.50 \\
\hline 4 & 60 & 0.5 & 0.1 & & 1.83 & 1.57 & 1.81 & 1.80 \\
\hline
\end{tabular}


Table 4. Results of the minimum thicknesses $t_{\min }(\mathrm{mm})$ obtained from the simulation by the FEM (the results are represented in the values in bold).

\begin{tabular}{|c|c|c|c|c|c|c|c|c|}
\hline \multicolumn{4}{|c|}{ Inner Array } & \multicolumn{5}{|c|}{ Outer Array } \\
\hline \multirow{4}{*}{ No. } & \multicolumn{3}{|c|}{ Control Factors } & \multicolumn{5}{|c|}{ Noise Factors } \\
\hline & & & & $n$ & 0.088 & 0.146 & 0.146 & 0.088 \\
\hline & $P(\mathrm{MPa})$ & $\rho_{\text {sh-rubb }}$ & $\rho_{\text {sh-blo }}$ & $K(\mathbf{M P a})$ & 636 & 726 & 636 & 726 \\
\hline & & & & $E(\mathrm{GPa})$ & 61 & 61 & 71 & 71 \\
\hline 1 & 50 & 0.2 & 0.1 & & 0.90 & 0.83 & 0.86 & 0.84 \\
\hline 2 & 50 & 0.5 & 0.2 & & 0.86 & 0.88 & 0.87 & 0.84 \\
\hline 3 & 60 & 0.2 & 0.2 & & 0.87 & 0.86 & 0.88 & 0.88 \\
\hline 4 & 60 & 0.5 & 0.1 & & 0.88 & 0.90 & 0.90 & 0.90 \\
\hline
\end{tabular}

Table 5. Values of the multiple optimization function (the results are represented in the values in bold).

\begin{tabular}{|c|c|c|c|c|c|c|c|c|c|c|}
\hline \multirow{5}{*}{ No. } & \multicolumn{3}{|c|}{ Inner Array } & \multicolumn{5}{|c|}{ Outer Array } & \multirow{5}{*}{ SN } & \multirow{5}{*}{ Media } \\
\hline & & ntrol fact & & & & factor & & & & \\
\hline & \multirow{3}{*}{$\begin{array}{c}P \\
(\mathrm{MPa})\end{array}$} & \multirow{3}{*}{$\rho_{\text {sh-rubb }}$} & \multirow{3}{*}{$\rho_{\text {sh-blo }}$} & $n$ & 0.088 & 0.146 & 0.146 & 0.088 & & \\
\hline & & & & K (MPa) & 636 & 726 & 636 & 726 & & \\
\hline & & & & $E(\mathrm{GPa})$ & 61 & 61 & 71 & 71 & & \\
\hline 1 & 50 & 0.2 & 0.1 & & 0.48 & 1.30 & 0.89 & 1.16 & -0.07 & 0.96 \\
\hline 2 & 50 & 0.5 & 0.2 & & 1.24 & 0.73 & 0.78 & 1.50 & -0.91 & 1.06 \\
\hline 3 & 60 & 0.2 & 0.2 & & 0.79 & 1.02 & 0.67 & 0.66 & 1.94 & 0.79 \\
\hline 4 & 60 & 0.5 & 0.1 & & 0.67 & 0.47 & 0.47 & 0.57 & 5.18 & 0.54 \\
\hline
\end{tabular}

Analyzing the obtained results, it was observed that to maximize the SN index, the pressure had to be placed at the highest level (with a contribution of 75\%), and the friction coefficient between the sheet and the block at the lowest level (with a contribution of 19\%). In addition, the friction coefficient between the sheet and the rubber should have the smallest contribution of the three control factors (only 6\%). The main effect diagrams of the mean and the ANOVA indicate that in order to reduce the average of the optimization function, the pressure should be at the highest level (with a contribution of $77 \%$ ) and with the friction coefficient between the sheet and the block at the lowest level (with a contribution of $20 \%$ ), while the friction coefficient between the sheet and the rubber should have the smallest contribution ( $3 \%$ ). Therefore, the same trend was detected in the behavior of the different control factors.

With these results, it can be established that the pressure and the friction coefficient between the sheet and the block are class I factors, since they affect both the mean and the variation. To minimize their effects, the pressure should be placed at the highest level, while the friction between the sheet and the block should be arranged at the lowest level, facilitating the entrance of the sheet material in the cavity of the shaping block. The friction between the sheet and the block does not significantly affect the average or the variation, so it should be at the most economical level. In this sense, the most economical level would be the highest level, without lubricant and with greater frag of the sheet by the rubber inside the cavity of the conformation block.

With the levels of the optimal control factors found (i.e. $60 \mathrm{MPa}$ for P, 0.5 for $\rho_{\text {sh-rubb }}$, and 0.1 for $\rho_{\text {sh-blo }}$ ) the values of elastic recovery and thinning were obtained for the different noise factors (see Table 6). It was observed how the values of $d$ and $t_{\min }$ were minimal and insensitive to the noise factors variations. In the case of elastic recovery, the use of the optimal parameters of the control factors caused the values of $d$ to oscillate between 1.57 and $1.81 \mathrm{~mm}$, while in the rest of the tests performed with less optimal values, $\mathrm{d}$ increments were obtained between $3.83 \%$ and $296.17 \%$ (see Table 3 ). The values of the elastic recovery would serve to compensate the conformation block. 


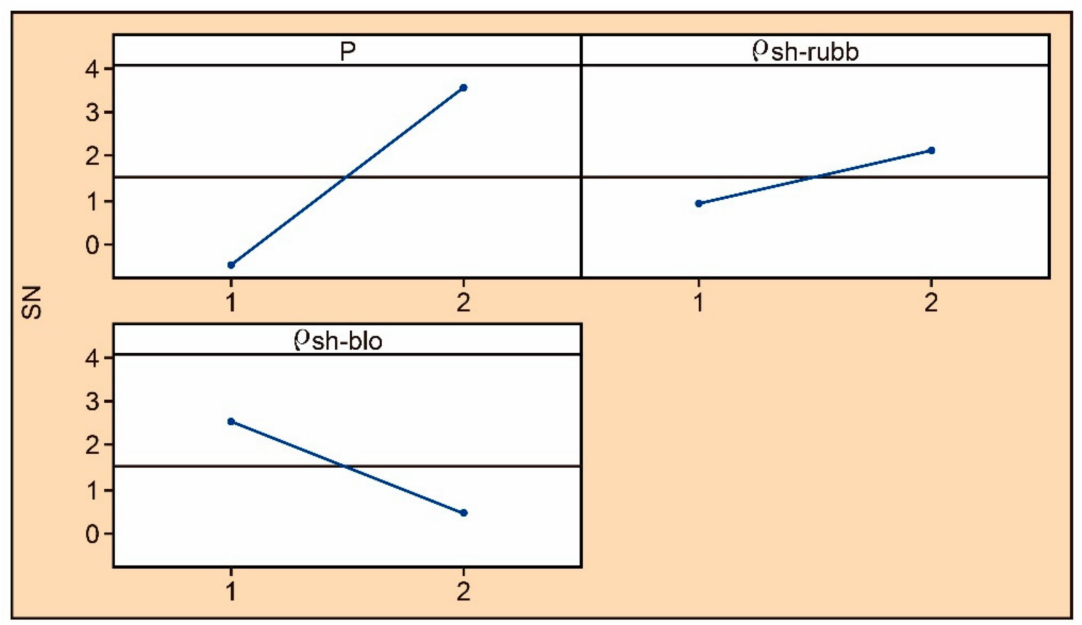

(a)

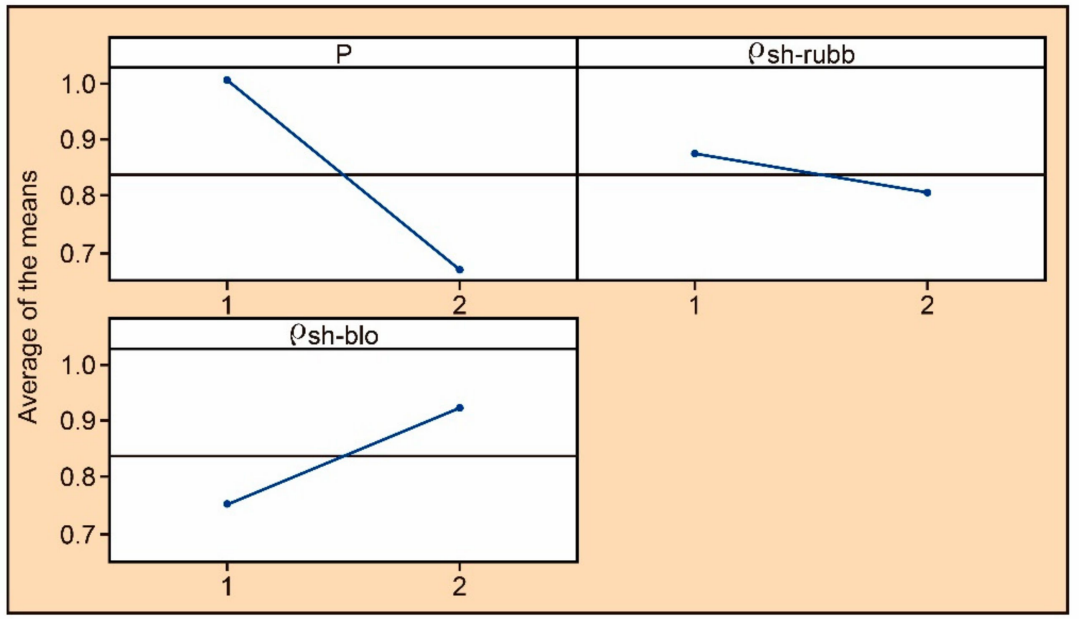

(b)

Figure 7. Main effects diagrams: (a) main effects for SN of the optimization function; and (b) main effects for the mean of the optimization function.

Table 6. Results of elastic recovery and thinning obtained with the optimal values of control factors.

\begin{tabular}{cccccccc}
\hline \multicolumn{4}{c}{ Elastic Recovery $d(\mathrm{~mm})$} \\
\hline $\begin{array}{c}\text { Combination } \\
\text { of Noise } \\
\text { Factors 1 }\end{array}$ & $\begin{array}{c}\text { Combination } \\
\text { of Noise } \\
\text { Factors 2 }\end{array}$ & $\begin{array}{c}\text { Combination } \\
\text { of Noise } \\
\text { Factors 3 }\end{array}$ & $\begin{array}{c}\text { Combination } \\
\text { of Noise } \\
\text { Factors 4 }\end{array}$ & $\begin{array}{c}\text { Combination } \\
\text { of Noise } \\
\text { Factors 1 }\end{array}$ & $\begin{array}{c}\text { Combination } \\
\text { of Noise } \\
\text { Factors 2 }\end{array}$ & $\begin{array}{c}\text { Combination } \\
\text { of Noise } \\
\text { Factors 3 }\end{array}$ & $\begin{array}{c}\text { Combination } \\
\text { of Noise } \\
\text { Factors 4 }\end{array}$ \\
\hline 1.83 & 1.57 & 1.81 & 1.80 & 0.88 & 0.90 & 0.90 & 0.90 \\
\hline
\end{tabular}

To assess the necking risk in the sheet stamping process in state T3, it is necessary to perform standardised trials to represent the sheet forming limit diagram (FLD). By performing the simulations using the finite element program with the optimal levels of control factors for different noise levels, Table 4, and obtaining the values of the largest and smallest true longitudinal deformations and representing them in the forming limit diagram, it is verified that if these values are above the forming limit curve, there will be necking risk, if they are below, there will be no necking risk and the sheet could be formed in state T3. 


\section{Conclusions}

A methodology that allows one to make a traditional process of the aeronautical industry robust has been established. The proposed modification of the robust design method of Taguchi parameters for multiobjective optimization allows one to simultaneously address the problems of elastic recovery and thinning in a simple way. Likewise, the use of simulations by means of nonlinear finite element methods allows reduction of the effort and costs of the experimental analyses. This allows a greater opportunity to optimize forming processes of other materials.

This methodology was applied in an AA2024-T3 of $1 \mathrm{~mm}$ thickness aluminium alloy sheet. An optimal condition of values for the control factors of the process was found. The combination of the pressure factors, the friction coefficient between the sheet and the block, and the friction coefficient between the sheet and rubber should adopt values of $60 \mathrm{MPa}, 0.1$, and 0.5 , respectively. The use of this configuration for different process conditions of noise factors caused the variations that presented the elastic deformation and the minimum thickness to be as low as possible. In this sense, the use of the optimal parameters of the control factors caused the values of elastic deformation to oscillate between 1.57 and $1.81 \mathrm{~mm}$, while the values of minimum thickness oscillated between 0.88 and $0.90 \mathrm{~mm}$.

In conclusion, the results obtained in this investigation are of great interest for the aeronautical engineering sector. Our findings can reduce the defects produced in the aeronautical sheet hydroforming process. Finally, the methodology used (which is fast and economical) can be extrapolated to the production of other aeronautical products, constituting an opportunity for its optimization.

Author Contributions: All the authors contributed equally to this work. All the authors participated in preparing the research from the beginning to end, such as establishing the research design, method, and analysis. All the authors discussed and finalized the analysis results to prepare the manuscript in accordance with the research progress. All the authors have read and approved the final manuscript.

Funding: This research received no external funding.

Acknowledgments: The authors would like to acknowledge the University of Cadiz for financing the publication of this study.

Conflicts of Interest: The authors declare no conflict of interest.

\section{References}

1. Ramezani, M.; Ripin, Z.M. Rubber-Pad Forming Processes: Technology and Applications; Woodhead Publishing Limited, Ed.; Elsevier: Oxford, UK, 2012; ISBN 9780857090942.

2. Gelin, J.-C. Advances and Progresses in Sheet and Tube Hydroforming Processes. In Advances in Material Forming; Springer: Paris, France, 2007; pp. 193-205.

3. Mahabunphachai, S.; Koç, M. Investigation of size effects on material behavior of thin sheet metals using hydraulic bulge testing at micro/meso-scales. Int. J. Mach. Tools Manuf. 2008, 48, 1014-1029. [CrossRef]

4. Xu, Z.; Peng, L.; Yi, P.; Lai, X. An investigation on the formability of sheet metals in the micro/meso scale hydroforming process. Int. J. Mech. Sci. 2019, 150, 265-276. [CrossRef]

5. Capece Minutolo, F.; Durante, M.; Formisano, A.; Langella, A. Optimization of a Hydroforming Process to Realize Asymmetrical Aeronautical Components by FE Analysis. In Intelligent Production Machines and Systems, 2nd I*PROMS Virtual International Conference 3-14 July 2006; Elsevier: Amsterdam, The Netherlands, 2006; pp. 241-246. [CrossRef]

6. Reveles Arredondo, J.F.; Ledesma Orozco, E.R.; Aguilera Gomez, E.; Saldaña Robles, A.; Castillo Hinojosa, I. Análisis teórico-numérico-experimental de un proceso de hidroconformado usando diámetro equivalente. DYNA Ing. Ind. 2015, 90, 67-77. [CrossRef]

7. Taguchi, G. Introduction to Quality Engineering: Designing Quality into Products and Processes; Quality Resources: New York, NY, USA, 1986.

8. Taguchi, G. System of Experimental Design: Engineering Methods to Optimize Quality and Minimize Costs; Quality Resources: New York, NY, USA, 1987. 
9. Venkateshwar Reddy, P.; Veerabhadra Reddy, B.; Srinivasa Rao, P. A Numerical Study on Tube Hydroforming Process to optimize the Process Parameters by Taguchi Method. Mater. Today Proc. 2018, 5, 25376-25381. [CrossRef]

10. Tilak, K.B.G.; Nagaraju, D. Investigation on Aluminium Alloy 1100 Using Taguchi Robust Design Methodology on CNC Milling. Mater. Today Proc. 2018, 5, 12719-12724. [CrossRef]

11. Wang, M.; Li, D.S.; Li, X.Q.; Yang, W.J. Probabilistic design of uncertainty for aluminum alloy sheet in rubber fluid forming process. Rev. Adv. Mater. Sci. 2013, 33, 442-451.

12. Rao, R.S.; Kumar, C.G.; Prakasham, R.S.; Hobbs, P.J. The Taguchi methodology as a statistical tool for biotechnological applications: A critical appraisal. Biotechnol. J. 2008, 3, 510-523. [CrossRef] [PubMed]

13. Box, G.; Bisgaard, S.; Fung, C. An explanation and critique of Taguchi's contributions to quality engineering. Qual. Reliab. Eng. Int. 1988, 4, 123-131. [CrossRef]

14. Swan, D.A.; Savage, G.J. Continuous Taguchi-A model-based approach to Taguchi's 'quality by design'with arbitrary distributions. Qual. Reliab. Eng. Int. 1998, 14, 29-41. [CrossRef]

15. Zoras, S. A review of building earth-contact heat transfer. Adv. Build. Energy Res. 2009, 3, 289-314. [CrossRef]

16. Venkata Mohan, S.; Chandrasekhara Rao, N.; Krishna Prasad, K.; Murali Krishna, P.; Sreenivas Rao, R.; Sarma, P.N. Anaerobic treatment of complex chemical wastewater in a sequencing batch biofilm reactor: Process optimization and evaluation of factor interactions using the Taguchi dynamic DOE methodology. Biotechnol. Bioeng. 2005, 90, 732-745. [CrossRef] [PubMed]

17. Taguchi, G.; Wu, Y. Introduction to Off-Line Quality Control; Central Japan Quality Control Association: Nagoya, Japan, 1979.

18. Antony Mike Kaye, J.; Frangou, A. A strategic methodology to the use of advanced statistical quality improvement techniques. TQM Mag. 1998, 10, 169-176. [CrossRef]

19. Aggarwal, A.; Singh, H.; Kumar, P.; Singh, M. Optimizing power consumption for CNC turned parts using response surface methodology and Taguchi's technique-A comparative analysis. J. Mater. Process. Technol. 2008, 200, 373-384. [CrossRef]

20. Fung, C.P.; Kang, P.C. Multi-response optimization in friction properties of PBT composites using Taguchi method and principle component analysis. J. Mater. Process. Technol. 2005, 170, 602-610. [CrossRef]

21. Reddy, P.B.S.; Nishina, K.; Subash Babu, A. Unification of robust design and goal programming for multiresponse optimization-A case study. Qual. Reliab. Eng. Int. 1997, 13, 371-383. [CrossRef]

22. Mitra, A.C.; Jawarkar, M.; Soni, T.; Kiranchand, G.R. Implementation of Taguchi Method for Robust Suspension Design. Procedia Eng. 2016, 144, 77-84. [CrossRef]

23. Katoueizadeh, E.; Zebarjad, S.M.; Janghorban, K. Optimization of synthesis conditions of N-doped $\mathrm{TiO}_{2}$ nanoparticles using Taguchi robust design. Mater. Chem. Phys. 2017, 201, 69-77. [CrossRef]

24. Hong, Y.; Beltran, A.A.; Paglinawan, A.C. A robust design of maximum power point tracking using Taguchi method for stand-alone PV system. Appl. Energy 2018, 211, 50-63. [CrossRef]

25. Sun, G.; Fang, J.; Tian, X.; Li, G.; Li, Q. Discrete robust optimization algorithm based on Taguchi method for structural crashworthiness design. Expert Syst. Appl. 2015, 42, 4482-4492. [CrossRef]

26. Ebrahimiasl, S.; Zin, W.; Yunus, W.; Kassim, A.; Zainal, Z. Prediction of grain size, thickness and absorbance of nanocrystalline tin oxide thin fi $\mathrm{lm}$ by Taguchi robust design. Solid State Sci. 2010, 12, 1323-1327. [CrossRef]

27. Naik, A.B.; Reddy, A.C. Optimization of tensile strength in TIG welding using the Taguchi method and analysis of variance (ANOVA). Therm. Sci. Eng. Prog. 2018, 8, 327-339. [CrossRef]

28. Liu, Y.; Liu, C.; Liu, W.; Ma, Y.; Tang, S.; Liang, C.; Cai, Q. Optimization of parameters in laser powder deposition AlSi10Mg alloy using Taguchi method. Opt. Laser Technol. 2019, 111, 470-480. [CrossRef]

29. Kumar, S.; Agarwal, S.; Srivastava, S. ScienceDirect Analysis of Surface Roughness during Turning Operation by Taguchi Method. Mater. Today Proc. 2018, 5, 28089-28097. [CrossRef]

30. Derdour, F.Z.; Kezzar, M.; Khochemane, L. Optimization of penetration rate in rotary percussive drilling using two techniques: Taguchi analysis and response surface methodology (RMS). Powder Technol. 2018, 339, 846-853. [CrossRef]

(C) 2019 by the authors. Licensee MDPI, Basel, Switzerland. This article is an open access article distributed under the terms and conditions of the Creative Commons Attribution (CC BY) license (http://creativecommons.org/licenses/by/4.0/). 